\title{
PERSYVE - Design and validation of a questionnaire about adverse effects of antihypertensive drugs
}

Daniela DUARTE-SILVA, Adolfo FIGUEIRAS, Maria T. HERDEIRO, António TEIXEIRA RODRIGUES, Fábio SILVA BRANCO, Jorge POLÓNIA, Isabel V. FIGUEIREDO.

\begin{abstract}
*
Objective: The aim of this study was to design and validate a questionnaire to measure perceived symptoms associated with antihypertensive drugs (PERSYVE). Methods: The PERSYVE development and validation included four stages: 1) item development (bibliographic review and questionnaire elaboration); 2) face and content validation; 3 ) field testing (pre-test); and 4) test-retest validation, assessment of internal consistency (Cronbach's alpha) and reproducibility over time (intraclass correlation coefficient and Cohen's kappa coefficient).

Results: PERSYVE is divided into six sections according to results obtained from the literature review: (1) drug adherence, (2) perceived symptoms and how they affect quality of life (five-point Likert scale), (3) communication with health professionals, (4) perception of symptoms as adverse reactions, (5) influence on therapy compliance, and (6) adoption of non-pharmacological methods for blood pressure control. Content and face validation of the questionnaire led to some vocabulary changes and the introduction of section 2.1. Field-testing $(n=26)$ revealed high comprehensibility of the questions. The Cronbach's alpha, calculated for section 2 (five-point Likert scale) was 0.850 . PERSYVE was reproducible $(n=167)$ : kappa values presented fair to substantial reproducibility and, in section 2 , ICC values resulted in good to excellent reproducibility.
\end{abstract}

*Daniela DUARTE-SILVA. PharmD, MSc. Laboratory of Pharmacology, Faculty of Pharmacy, University of Coimbra; \& CESPU, Instituto de Investigação e Formação Avançada em Ciências e Tecnologias da Saúde. Coimbra (Portugal).daniela.duarte@ipsn.cespu.pt

Adolfo FIGUEIRAS. PhD. Faculty of Medicine, University of Santiago de Compostela; \& Consortium for Biomedical Research in Epidemiology \& Public Health (CIBER en Epidemiología y Salud Pública - CIBERESP). Santiago de Compostela (Spain). Adolfo.figueiras@usc.es Maria Teresa HERDEIRO. PharmD, MSc, PhD. CESPU, Instituto de Investigação e Formação Avançada em Ciências e Tecnologias da Saúde; \& Center for Cell Biology, University of Aveiro; \& Center for Health Technology. Porto (Portugal). teresaherdeiro@ua.pt António TEIXEIRA RODRIGUES. PharmD. Center for Cell Biology, University of Aveiro; \& Faculty of Pharmacy, University of Coimbra. Coimbra (Portugal).

at.afonso@ua.pt

Fábio SILVA BRANCO. PharmD. Laboratory of Pharmacology, Faculty of Pharmacy, University of Coimbra. Coimbra (Portugal). fabiosbranco@gmail.com Jorge POLÓNIA. MD, PhD. Faculty of Medicine, University of Porto; \& Unit of Hypertension, Pedro Hispano General Hospital. Matosinhos (Portugal).

jjpolonia@gmail.com

Isabel Vitória FIGUEIREDO. PharmD, PhD. Laboratory of Pharmacology, Faculty of Pharmacy, University of Coimbra; \& Center for Pharmaceutical Studies, University of Coimbra; \& IBILI - Institute for Biomedical Imaging and Life Sciences, Universidade de Coimbra. Coimbra (Portugal). isabel@ff.uc.pt
Conclusion: Results showed that PERSYVE is a wellstructured, objective, patient-friendly, valid and reliable questionnaire. PERSYVE can be a very useful instrument in hypertensive patients' monitoring and in the screening of adverse effects

Keywords: Antihypertensive Agents; Drug-Related Side Effects and Adverse Reactions; Medication Adherence; Questionnaires; Validation Studies as Topic; Portugal

\section{INTRODUCTION}

Hypertension is a pathological condition and a highly prevalent cardiovascular risk factor worldwide $^{1}$, related to mortality, cerebrovascular and cardiovascular diseases ${ }^{2}$, cognitive function impairment and dementia. ${ }^{3}$

Antihypertensive therapy leads to high success rates in the treatment of hypertension. However, adverse effects arising from the use of these drugs have often been reported ${ }^{4}$, being one of the most common causes of antihypertensive therapy replacement or dropout. ${ }^{5,6}$ Therefore, it is crucial to know how antihypertensive therapies and drug use affect patients' quality of life (QoL) and therapy compliance. ${ }^{7}$ In clinical practice, methods to monitor treatment adherence, such as electronic monitoring devices, pill counts and ascertaining rates of refilling prescriptions, are useful but difficult to perform. The most practical way to collect this information is by patients' self-reporting by means of interviews or self-administered questionnaires. ${ }^{8,9}$

For the reasons set out in the last paragraph, PERSYVE was designed and validated as an original questionnaire to measure patients' compliance, adverse drug events, communication skills and behavioural issues regarding antihypertensive drugs.

There are several studies showing the usefulness of questionnaires to assess rational drug use ${ }^{10,11}$, patients' perception of symptoms and of adverse drug reactions ${ }^{12,13}$, to measure patients' knowledge about their disease ${ }^{14}$ and as a complement to diagnosis or disease management. ${ }^{15,16}$ PERSYVE differs from the existing questionnaires because it provides a unique tool with which to assess different factors that influence therapy and enables active research (through a check-list) into common adverse effects of antihypertensive drugs. 


\section{METHODS}

To develop and validate PERSYVE, four stages were performed: 1) item development; 2) face and content validation; 3) field testing (pre-test); and 4) test-retest validation survey.

\section{Stage 1: Item development}

PERSYVE development started with a bibliographic review on PubMed, Ovid and ProQuest databases, using the following keywords: antihypertensive drugs; patient adherence; adverse effects; and questionnaire. The bibliographic review aimed the elaboration of the questionnaire items, which included the assessment of patients' compliance issues, adverse drug events related to antihypertensive drugs, communication skills and behavioural issues regarding antihypertensive drug use. Bibliography used on the review focused on patient self-reported adverse effects, adherence to therapeutics, frequently observed symptoms and adverse reactions related to antihypertensive drugs.

PERSYVE was designed to be filled in by health professionals as a communication instrument with patients, exploring six different issues related to antihypertensive drug use and patients' perceptions of adverse reactions. These six issues were examined through six approaches:

1) Haynes-Sackett methodology self-reported compliance method, used to assess the percentage of therapy adherence through evaluating the percentage of missed doses ${ }^{9,17}$;

2) Assessment of how QoL is affected by 25 side effects frequently experienced during antihypertensive therapy;

3) Communication of adverse drugs reactions;

4) Discovery of which symptoms, if any, patients felt and related to antihypertensive therapy;

5) Assessment of how symptoms affect the compliance to antihypertensive drug therapy;

6) Assessment of complementary therapy, i.e., nonpharmacological therapy, to control blood pressure.

In section 2, a five-point Likert scale, ranging from "never affects" to "always affects", was used to assess the impact of each symptom on patients' QoL. Other sections used nominal yes/no variables.

\section{Stage 2: Item content and face validation}

Content validity is defined as the extent to which the concepts of interest are comprehensively represented by the scales set out. Three pharmacy PhDs, two in pharmacology and one in pharmacoepidemiology, and three physicians, one $\mathrm{PhD}$ expert in hypertension, one cardiologist and one general practitioner, were asked to evaluate the content validity of the questionnaire. The evaluation was based on the following five key points ${ }^{18}$ : the measurement aims of the questionnaire (whether PERSYVE measures patients' compliance, adverse drug events, communication skills and behavioural issues regarding antihypertensive drug use), the target population (is the questionnaire tailored for the hypertensive population?), concepts intended for measurement (does the questionnaire cover all important aspects related to antihypertensive drug use?), question selection, and finally concision and interpretability.

A language professor and a clinical psychologist, both $\mathrm{PhD}$, evaluated the interface validity of the questionnaire, which included the evaluation of grammar, the logical sequence of the statements and overall appropriateness. ${ }^{19}$

\section{Stage 3: Field testing (pre-test)}

At this stage, the - internally - validated version of the questionnaire was tested to evaluate its clarity, comprehensiveness and mean interview duration. This served to assess the acceptability of the questions, to ascertain whether there were any perceived problems during the interview and to clarify whether there were relevant aspects missing.

The field testing was conducted in a general practice setting, by the same interviewer who developed the subsequent questionnaires (DDS). Seven general practitioners and 31 hypertensive patients recruited by consecutive sampling participated in the test.

Patients over 18 years of age, clinically diagnosed with essential hypertension and under pharmacological antihypertensive therapy for at least six months were invited to participate. Individuals who did not meet these inclusion criteria, such as those with hypertension as a consequence of other diseases or conditions, those with mental disabilities and those who refused to participate, were not enrolled in the study.

\section{Stage 4: Test-retest validation survey}

\section{Participants' selection}

The population consisted of patients from a primary health care unit in Matosinhos, Portugal. Hypertensive patients were recruited by consecutive sampling over a two-month period. The inclusion criteria were the same as those in the pilot test developed in the field testing stage. All 20 physicians who had performed adult health consultations during this period agreed to participate.

Patients were invited by their physician to enrol in the study. The interviews were performed by a pharmacist researcher (DDS) in similar conditions to a medical appointment. Information was gathered from patients by interview after their medical appointments. The researcher was unaware of the patients' clinical cases. At the end of the first interview, patients were scheduled for a second interview. As in previously published studies ${ }^{20,21}$, a retest was performed two to four weeks after the first interview.

\section{Ethics}

The study was conducted after the approval of the Ethics Committee. A brief explanation of the study was given to all involved, physicians and patients, and all were asked to sign a consent form.

Psychometric tests and statistical analysis 
Psychometric tests allowed the assessment of the internal consistency and reproducibility of PERSYVE items.

The internal consistency of the PERSYVE was evaluated by Cronbach's alpha coefficient. ${ }^{22,23}$ Cronbach's alpha is the most widely used objective measurement of internal consistency. It varies from 0 to 1 and describes the extent to which all the items in a test measure the same concept or construct. For an instrument with nominal/ordinal outcome variables (as in the 1-5 Likert scale), it is acceptable to obtain values of Cronbach's alpha above 0.7 . Since the questionnaire was not a single construct, $\alpha$ value was only calculated for the 25 items in section 2.

The reproducibility of the questionnaire was carried out by test-retest method. In all sections of PERSYVE, excluding section 2 , the reproducibility was measured using the Cohen's kappa coefficient. ${ }^{24}$ This coefficient, $\mathrm{K}$, is frequently used as a reproducibility measurement for repeated assessments of the same variable and could be defined as an inter-rater statistical method used to estimate the agreement level of categorical data. The reproducibility in section 2 of PERSYVE was measured using the one-way random effects model for single measures, known as intraclass correlation coefficients (ICCs), a statistical method of measuring reproducibility of replicates from the same subject. A one-way ICC was chosen because the effect of the trials is not crossed with subjects (i.e., a replication study; hence, one-way) and the analysis is used to generalize from a trial based on a sample (thus, random). All interviews were conducted by the same researcher (DDS); hence, inter-observer reliability was not evaluated.

The collected data was coded and inserted in a database. Data was randomly checked to evaluate transcription errors. Statistical analysis was performed using IBM SPSS Statistics for Windows, Version 19.0, Armonk, NY: IBM Corp.

\section{RESULTS}

\section{Stage 1: Item development}

PERSYVE is mainly composed of closed questions, divided into six main sections to assess patient compliance, adverse drug events, communication skills and behavioural issues regarding antihypertensive drug use. These sections are as follows:

1. Many patients have difficulties taking their medicines as the physician recommended. In the past three months, was there any day or period of time when you did not take the drugs for blood pressure as recommended? Section 1 evaluates the adherence to therapy, the reasons for noncompliance and the patients' opinion about the influence of adherence on their blood pressure control.

2. In the last three months did you feel any of the following symptoms? Section 2 attempted to understand which symptoms affect patients' QoL, and how (using a five-point Likert scale).

3. Have you ever spoken with someone about these symptoms? Section 3 studied whether the symptoms were discussed with health professionals around the patient, exploring the reasons why patients did not report their symptoms.

4. Do you think the symptoms you have had may be caused by your medication? Section 4 attempts to evaluate whether patients perceived their symptoms as adverse effects or whether they did not see a causal relationship.

5. Have these symptoms led you to change or stop your medicine intake? Section 5 assessed whether the described symptoms contributed to drug misuse and non-compliance.

6 . Do you take other measures to help reduce your blood pressure? Section 6 explored patients' actions for non-pharmacological blood pressure control.

\section{Stage 2: Item content and face validation}

The expert consensus revealed that PERSYVE has sound face and content validity. The general opinion was that the questionnaire was well structured and included all important issues regarding patients' compliance, adverse drug events, communication skills and behavioural issues. Experts suggested the introduction of a question about how symptoms affected patients' QoL resulting in item 2.1, evaluated using a five-point Likert scale. The evaluation of the face validity by the panel of experts resulted in minor vocabulary and grammatical changes; no significant change was made to the questionnaire.

\section{Stage 3: Field testing}

\section{Participants}

Interviews were carried out with essential hypertension patients $(n=31)$. Five individuals did not meet the inclusion criterion "6 months or less under antihypertensive drug therapy". Therefore, data from the remaining individuals was used $(n=26)$.

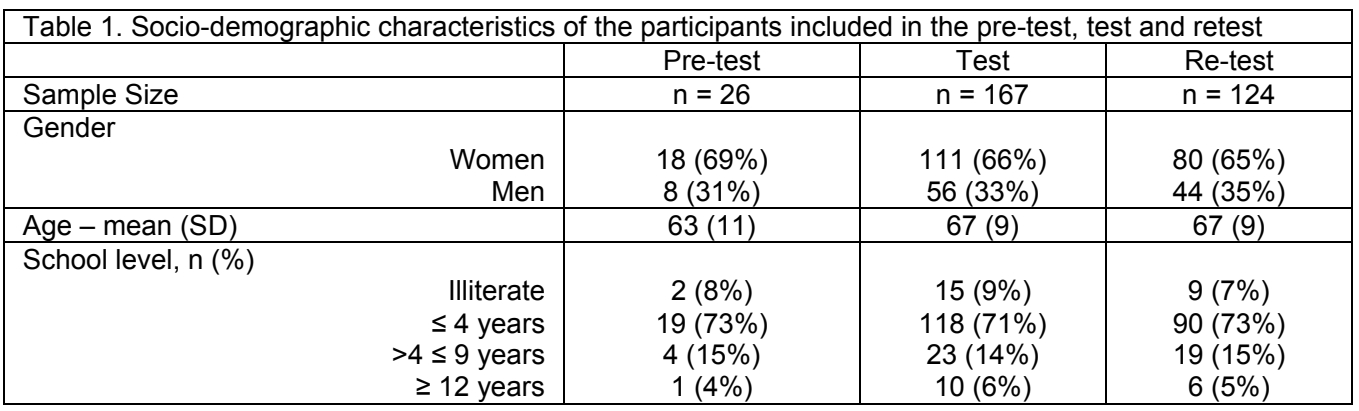


Duarte-Silva D, Figueiras A, Herdeiro MT, Teixeira Rodrigues A, Silva Branco F, Polónia J, Figueiredo IV. PERSYVE - Design and validation of a questionnaire about adverse effects of antihypertensive drugs. Pharmacy Practice 2014 Apr-Jun;12(2):396

\begin{tabular}{|c|c|}
\hline Section & Cohen's Kappa \\
\hline Sample size & $\mathrm{n}=124$ \\
\hline $\begin{array}{l}\text { 1. Many patients have difficulties taking their medicines as the doctor recommended. In } \\
\text { the past three months, was there any day or period of time when you did not take the } \\
\text { drugs for blood pressure as recommended? }\end{array}$ & $0.462^{* \star \star}$ \\
\hline Forgetfulness & $0.412^{*}$ \\
\hline Economic reasons & $0.520 * *$ \\
\hline Drugs cause discomfort or malaise & $0.474^{* *}$ \\
\hline Blood pressure was normal & $0.516^{* *}$ \\
\hline $\begin{array}{l}\text { Blood pressure was too low } \\
\text { Blood pressure remained high }\end{array}$ & $\underset{a}{0.651^{* * *}}$ \\
\hline 3. Have you ever spoken with someone about these symptoms? & $0.330^{\star * *}$ \\
\hline Specialist doctor & $0.386^{* *}$ \\
\hline General practitioner & $0.260^{* *}$ \\
\hline Other doctor & $0.517^{* * *}$ \\
\hline Pharmacist & $0.381^{* *}$ \\
\hline Nurse & $0.561^{* * *}$ \\
\hline Family/friends & $0.286^{*}$ \\
\hline 4. Do you think the symptoms you had may be caused by your medications? & $0.461^{* * *}$ \\
\hline $\begin{array}{l}\text { 5. Have these symptoms led you to change the intake of medicines or stop taking } \\
\text { them? }\end{array}$ & $0.228^{* *}$ \\
\hline 6. Do you take other measures to help reduce your blood pressure? & \\
\hline Exercise & $0.724^{* * *}$ \\
\hline Diet & $0.747^{* * *}$ \\
\hline Avoid salt intake & $0.654^{* * *}$ \\
\hline Weight control (try not to get fat) & $0.539^{* * *}$ \\
\hline Avoid stress & $0.394^{* * *}$ \\
\hline Take a dietary supplement to control blood pressure & $0.466^{* * *}$ \\
\hline
\end{tabular}

Table 1 describes the socio-demographic characteristics of the individuals included in the pretest.

\section{PERSYVE field testing}

During PERSYVE field-testing, none of the patients refused to answer the questionnaire and questions were well understood by patients. The investigator (DDS) did not notice any difficulty in the interpretation or comprehension of the questions by the participants. Filling in the questionnaire took, on average, 10 minutes.

\section{Stage 4: Test-retest validation survey}

Participants

Two hundred and nine hypertensive patients $(n=209)$ were invited to participate in the study. Of these, four refused to participate and two missed the interview. Two hundred and three $(n=203)$ patients attended the first interview (test). Of these, 34 were excluded because they did not meet the inclusion criteria: three patients had discontinued antihypertensive drugs and 31 had started or changed antihypertensive therapy less than six months prior to the interview date.

At the second interview (retest), we collected data from 135 of the remaining 169 patients. Thirty-four patients did not attend the interview. There were nine cases of therapy change between the first and the second interview and it was found that two individuals had started a new antihypertensive drug less than six months before (information had been omitted at the first interview), hence, in these cases interviews were not considered.

Summarily, there were 167 valid first interviews (test) and 124 valid second interviews (retest).
Socio-demographic characteristics are presented in Table 1. Socio-demographic characteristics were not used to assess any relationship with the dimensions evaluated by PERSYVE. However, as shown in Table 1, socio-demographic characteristics are very similar in all stages of this study (pre-test, test and retest).

Internal consistency

The Cronbach's alpha calculated for the Likert scale of symptoms (section 2) was considered acceptable (alpha $=0.850$ )

Reproducibility

Table 2 presents the results obtained for kappa. Considering the classification presented by Landis $\& \mathrm{Koch}^{24}$, kappa values obtained revealed, at least, fair to substantial reproducibility, which represents the level of agreement between answers.

In section 2 of PERSYVE, ICCs revealed good to excellent reproducibility of all evaluated symptoms (Table 3).

\section{DISCUSSION}

According to the World Health Organization, there is a need for the development of valid and reliable instruments to collect data on the determinants of hypertension treatment. ${ }^{25}$ Questionnaires intended for the clinical setting must be patient-friendly, valid, reliable and open to minor changes. The evaluation should also be easy to perform and the results must be easily coded and interpreted. ${ }^{26}$ All stages of the PERSYVE validation confirmed that this instrument is a well-structured, clear, objective, easy to implement, valid and reliable tool. 


\begin{tabular}{|c|c|}
\hline Symptoms & ICC $(95 \% \mathrm{Cl})$ \\
\hline Tiredness & $0.738(.627 ; .816)^{\star \star \star}$ \\
\hline Feeling faint & $0.624(.465 ; .736)^{\star \star \star}$ \\
\hline Sweats & $0.840(.772 ; .888)^{\star \star \star}$ \\
\hline Gripes & $0.774(.677 ; .841)^{\star * \star}$ \\
\hline Nausea & $0.627(.469 ; .739)^{\star \star \star}$ \\
\hline Diarrhoea & $0.493(.277 ; .644)^{\star \star *}$ \\
\hline Constipation & $0.897(.853 ; .928)^{\star * \star}$ \\
\hline Palpitations & $0.566(.381 ; .695)^{\star \star \star}$ \\
\hline Swollen feet or legs & $0.779(.685 ; .845)^{\star \star \star}$ \\
\hline Cold hands or feet & $0.674(.536 ; .772)^{\star \star \star}$ \\
\hline Muscle pain & $0.824(.750 ; .877)^{\star \star *}$ \\
\hline Cramps & $0.799(.713 ; .859)^{\star \star \star}$ \\
\hline Headaches & $0.834(.763 ; .883)^{\star \star *}$ \\
\hline Dizziness & $0.596(.424 ; .716)^{\star \star \star}$ \\
\hline Anxiety & $0.794(.706 ; .855)^{\star \star \star}$ \\
\hline Sadness & $0.817(.740 ; .872)^{\star \star \star}$ \\
\hline Sleep poorly & $0.757(.654 ; .829)^{\star \star \star}$ \\
\hline $\begin{array}{l}\text { Shortness of breath or breathing } \\
\text { difficulty }\end{array}$ & $0.763(.662 ; .834)^{\star \star *}$ \\
\hline Persistent dry cough & $0.519(.375 ; .663)^{\star * \star}$ \\
\hline Itching & $0.761(.659 ; .832)^{\star \star \star}$ \\
\hline Skin rash & $0.621(.460 ; .734)^{\star \star \star}$ \\
\hline Swollen or red face & $0.707(.582 ; .794)^{\star \star \star}$ \\
\hline Dry mouth & $0.813(.733 ; .869)^{\star \star \star}$ \\
\hline Frequent urination & $0.803(.719 ; .862)^{\star * \star}$ \\
\hline Decreased sexual desire or ability & $0.780(.687 ; .846)^{\star \star \star}$ \\
\hline $\begin{array}{l}{ }^{*}=p<0.05 ;{ }^{* *}=p<0.01 ;{ }^{* * *}=p<0 \\
\text { ICC }=\text { Intraclass correlation } \\
\text { confidence interval }\end{array}$ & cient; \\
\hline
\end{tabular}

PERSYVE may be used as a complement to anamnesis and as a screening method for adverse effects. It will also provide the clinical practitioner with patients' beliefs about other nonpharmacological treatments and evaluate therapy compliance. Patients tend to value symptoms more than physicians do when reporting daily health status. ${ }^{27}$ Patients' self-declarations of adverse drug reactions are already part of the pharmacovigilance mechanisms in some countries ${ }^{28}$ and selfdeclaration could be a very useful indicator of rational use of medicines. ${ }^{11}$ This supports the importance of promoting communication between health professionals and patients, and we consider PERSYVE a good means to that end. Moreover, it can help patients to cope with antihypertensive therapy and to improve compliance.

It is also important to draw attention to the results of the design and evaluation of the questionnaires, so they can be used as trustworthy resources for other researchers. ${ }^{30}$

Both experts' panels, which assessed the content and face validity of PERSYVE, made some suggestions for improving PERSYVE's acceptability, such as better interpretability and comprehensiveness of the questionnaire, and suggested raising its clinical interest by adding the evaluation of the effect of symptoms on the patients' QoL.

Psychometric analysis confirmed the internal consistency (Cronbach's alpha) and the reproducibility (kappa and ICC) of PERSYVE. PERSYVE Cronbach's alpha values indicated that there is internal consistency. For an instrument with nominal/ordinal outcome variables, it is acceptable to obtain values of Cronbach's alpha 0.7 or higher. ${ }^{23}$

The psychometric characteristics of PERSYVE are similar to those of other validated questionnaires that studied symptoms perceived by chronic patients ${ }^{29}$, patients' knowledge about their disease and treatment ${ }^{30,31}$ and other subjects related to the use of drugs. ${ }^{32,33}$

Regarding the limitations of this study, the consecutive selection of participants in a convenient sample, the performance of the recruitment by general practitioners and the characteristics of the sample population (such as advanced age), may introduce selection and response bias. ${ }^{34,35}$ Women comprised the majority of the interviewed subjects, but this is consistent with characteristics of the studied population. Concerning PERSYVE validation, its use in self-declaration was not evaluated due to patients' low literacy levels. Its external validity was not established either. The main limitation of the test-retest method is the potential for learning or recalling effects that can affect the test's result - the two weeks' interval between measurements is fundamental to this, since it is long enough to avoid carryover effects due to memory and short enough to exclude changes in patient behaviour.

\section{CONCLUSIONS}

PERSYVE is a reliable, patient-friendly questionnaire that is easily implemented in the clinical practice. Therefore, PERSYVE could be a very useful tool to assess dimensions related to antihypertensive therapy; more specifically, to assess perceived symptoms related to antihypertensive drugs, to screen for potential adverse effects and to better understand the factors that underlie poor compliance.

In the future, PERSYVE should be externally validated, tested in a patient fill out trial and in other countries in order to expand its applicability.

\section{ACKNOWLEDGMENTS}

The authors would like to thank Unidade Local de Matosinhos, especially Centro de Saúde de São Mamede de Infesta, where this study took place. The authors also wish to express their sincere thanks to Professor António Santos (CITS Northern Polytechnic Health Institute, Famalicão, Portugal) for the statistics training, and the experts who evaluated the content and face validity of the questionnaire. We also thank English Proofread editing services (www.englishproofread.com).

\section{CONFLICT OF INTEREST}

The authors declare no conflict of interest.

Funding: No funding was provided for this project.

\author{
PERSYVE - DISEÑO Y VALIDACIÓN DE UN \\ CUESTIONARIO SOBRE EFECTOS ADVERSOS \\ DE ANTIHIPERTENSIVOS
}




\section{RESUMEN}

Objetivo: El objetivo de este estudio fue diseñar y validar un cuestionario para medir los síntomas percibidos asicados a medicamentos antihipertensivos (PERSYVE).

Métodos: El desarrollo y validación de PERSYVE incluyó cuatro etapas: 1) desarrollo de ítems (revisión bibliográfica y elaboración del cuestionario); 2) validación de rostro y de contenido; 3 ) prueba de campo (pre-test); y 4) validación test-retest, evaluación de la consistencia interna (alfa de Chronbach) y reproductibilidad en el tiempo (coeficiente de correlación intra-clases y coeficiente kappa de Cohen).

Resultados: De acuerdo con los resultados obtenidos de la revisión de la literatura, PERSYVE se divide en seis secciones: (1) adherencia a medicamentos, (2) síntomas percibidos y como afectan a la calidad de vida (escala Likert de cinco puntos), (3) comunicación con los profesionales de la salud, (4) percepción de síntomas como reacciones adversas, (5) influencia en el cumplimiento del tratamiento, y (6) adopción de métodos no farmacológicos para el control de la presión arterial.
La validación de rostro y de contenido del cuestionario llevaron a algunos cambios de vocabulario y a la introducción de la sección 2.1. El ensayo de campo $(\mathrm{n}=26)$ reveló una alta comprensibilidad de las preguntas. El alfa de Cronbach calculado para la sección 2 (escala de Likert de 5 puntos) fue de 0,850 . PERSYVE fue reproducible $(\mathrm{n}=167)$ : valores de kappa presentaron una reproductibilidad sustancial y, en la sección 2 , los valores de ICC resultaron de buenos a excelentes.

Conclusión: Los resultados demostraron que PERSYVE es un cuestionario bien estructurado, objetivo, fácil de usar para el paciente, válido y confiable. PERSYVE puede ser un instrumento muy útil en la monitorización de pacientes hipertensos y en el rastreo de efectos adversos.

Palabras clave: Antihipertensivos; Efectos colaterales de y reacciones adversas de los medicamentos; Cumplimiento de la Medicación; Cuestionarios; Estudios de Validación como Asunto; Portugal

\section{References}

1. Whitworth JA; World Health Organization, International Society of Hypertension Writing Group.. 2003 World Health Organization (WHO)/International Society of Hypertension (ISH) statement on management of hypertension. J Hypertens. 2003;21(11):1983-1992. doi: 10.1097/01.hjh.0000084751.37215.d2

2. Ezzati M, Lopez AD, Rodgers A, Vander Hoorn S, Murray CJ. Selected major risk factors and global and regional burden of disease. Lancet. 2002;360(9343):1347-1360. doi: 10.1016/S0140-6736(02)11403-6

3. Poon IO. Effects of antihypertensive drug treatment on the risk of dementia and cognitive impairment. Pharmacotherapy. 2008;28(3):366-375. doi: 10.1592/phco.28.3.366

4. Cheung BM, Wong YL, Lau CP. Queen Mary Utilization of Antihypertensive Drugs Study: side-effects of antihypertensive drugs. J Clin Pharm Ther. 2005;30(4):391-399. doi: 10.1111/j.1365-2710.2005.00662.x

5. Ross SD, Akhras KS, Zhang S, Rozinsky M, Nalysnyk L. Discontinuation of antihypertensive drugs due to adverse events: a systematic review and meta-analysis. Pharmacotherapy. 2001;21(8):940-953.

6. Dusing $\mathrm{R}$, Weisser $\mathrm{B}$, Mengden $\mathrm{T}$, Vetter $\mathrm{H}$. Changes in antihypertensive therapy--the role of adverse effects and compliance. Blood Press. 1998;7(5-6):313-315.

7. Dragomir A, Côté R, Roy L, Blais L, Lalonde L, Bérard A, Perreault S. Impact of adherence to antihypertensive agents on clinical outcomes and hospitalization costs. Med Care. 2010;48(5):418-425. doi: 10.1097/MLR.0b013e3181d567bd

8. Fodor GJ, Kotrec M, Bacskai K, Dorner T, Lietava J, Sonkodi S, Rieder A, Turton P. Is interview a reliable method to verify the compliance with antihypertensive therapy? An international central-European study. J Hypertens. 2005;23(6):1261-1266

9. Piñeiro F, Gil V, Donis M, Orozco D, Pastor R, Merino J. [The validity of 6 indirect methods for assessing drug treatment compliance in arterial hypertension]. Aten Primaria. 1997;19(7):372-376.

10. Simpson SH, Johnson JA, Farris KB, Tsuyuki RT. Development and validation of a survey to assess barriers to drug use in patients with chronic heart failure. Pharmacotherapy. 2002;22(9):1163-1172.

11. Gascon Canovas JJ, Saturno Hernandez PJ, Sanchez Sanchez JA. [Usefulness of patients' reports in monitoring rational use of medicines]. Aten Primaria. 2001;27(6):395-402.

12. Jarernsiripornkul N, Kakaew W, Loalukkana W, Krska J. Adverse drug reaction monitoring: comparing doctor and patient reporting for new drugs. Pharmacoepidemiol Drug Saf. 2009;18(3):240-245. doi: 10.1002/pds.1708

13. Jarernsiripornkul N, Krska J, Capps PA, Richards RM, Lee A. Patient reporting of potential adverse drug reactions: a methodological study. Br J Clin Pharmacol. 2002;53(3):318-325.

14. Baez Saldana AR, Chapela Mendoza R, Herrera Kiengelher L, Ortiz Siordia R, Salas Hernandez J. [Development of a questionnaire to measure asthmatic patients' knowledge of their disease]. Arch Bronconeumol. 2007;43(5):248-255.

15. Okun ML, Kravitz HM, Sowers MF, Moul DE, Buysse DJ, Hall M. Psychometric evaluation of the Insomnia Symptom Questionnaire: a self-report measure to identify chronic insomnia. J Clin Sleep Med. 2009;5(1):41-51.

16. Bengtsson M, Ohlsson B, Ulander K. Development and psychometric testing of the Visual Analogue Scale for Irritable Bowel Syndrome (VAS-IBS). BMC Gastroenterol. 2007;7:16. doi: 10.1186/1471-230X-7-16

17. Sackett DL, Haynes RB, Gibson ES, Hackett BC, Taylor DW, Roberts RS, Johnson AL. Randomised clinical trial of strategies for improving medication compliance in primary hypertension. Lancet. 1975;1(7918):1205-1207.

18. Terwee CB, Bot SD, de Boer MR, van der Windt DA, Knol DL, Dekker J, Bouter LM, de Vet HC. Quality criteria were proposed for measurement properties of health status questionnaires. J Clin Epidemiol. 2007;60(1):34-42. doi: 10.1016/j.jclinepi.2006.03.012

19. Alumran A, Hou XY, Hurst C. Validity and reliability of instruments designed to measure factors influencing the overuse of antibiotics. J Infect Public Health. 2012;5(3):221-232. doi: 10.1016/j.jiph.2012.03.003 
20. Marx RG, Menezes A, Horovitz L, Jones EC, Warren RF. A comparison of two time intervals for test-retest reliability of health status instruments. J Clin Epidemiol. 2003;56(8):730-735.

21. dos Santos Pernas SI, Herdeiro MT, Lopez-Gonzalez E, da Cruz e Silva OA, Figueiras A. Attitudes of Portuguese health professionals toward adverse drug reaction reporting. Int J Clin Pharm. 2012;34(5):693-698. doi: 10.1007/s11096-012-9675-6

22. Cronbach LJ. Coefficient alpha and the internal structure of tests. Psychometrika. 1951;16(3):297-334.

23. Tavakol M, Dennick R. Making sense of Cronbach' alpha. Int J Med Educ. 2011;2:53-55. doi: 10.5116/ijme.4dfb.8dfd

24. Landis JR, Koch GG. The measurement of observer agreement for categorical data. Biometrics. 1977;33(1):159-174.

25. World Health Organization. Adherence to long-term therapies: evidence fo action. Geneva: WHO;2003.

26. Stone DH. Design a questionnaire. BMJ. 1993;307(6914):1264-1266.

27. Basch E, Jia X, Heller G, Barz A, Sit L, Fruscione M, Appawu M, lasonos A, Atkinson T, Goldfarb S, Culkin A, Kris MG, Schrag D. Adverse symptom event reporting by patients vs clinicians: relationships with clinical outcomes. J Natl Cancer Inst. 2009;101(23):1624-1632. doi: 10.1093/jnci/djp386

28. Blenkinsopp A, Wilkie $P$, Wang M, Routledge PA. Patient reporting of suspected adverse drug reactions: a review of published literature and international experience. Br J Clin Pharmacol. 2007;63(2):148-156. doi: 10.1111/j.13652125.2006.02746.x

29. Bengtsson M, Ohlsson B, Ulander K. Development and psychometric testing of the Visual Analogue Scale for Irritable Bowel Syndrome (VAS-IBS). BMC Gastroenterol. 2007;7:16. doi:10.1186/1471-230X-7-16

30. García Delgado P, Gastelurrutia Garralda MA, Baena Parejo MI, Fisac Lozano F, Martínez Martínez F. [Validation of a questionnaire to assess patient knowledge of their medicines]. Aten Primaria. 2009;41(12):661-668. doi: 10.1016/j.aprim.2009.03.011

31. Saldaña ARB, Mendoza RC, Kiengelher LH, Rebeca Ortiz Siordia, Hernández JS. Development of a Questionnaire to Measure Asthmatic Patients' Knowledge of Their Disease. Arch Bronconeumol. 2007;43(5):248-255.

32. Simpson SH, Johnson JA, Farris KB, Tsuyuki RT. Development and validation of a survey to assess barriers to drug use in patients with chronic heart failure. Pharmacotherapy. 2002;22(9):1163-1172.

33. Bharmal M, Payne K, Atkinson M, Desrosiers M-P, Morisky D, Gemmen E. Validation of an abbreviated Treatment Satisfaction Questionnaire for Medication (TSQM-9) among patients on antihypertensive medications. Health Qual Life Outcomes. 2009;7:36. doi: 10.1186/1477-7525-7-36

34. Brown JB, Adams ME. Patients as Reliable Reporters of Medical Care Process: Recall of Ambulatory Encounter Events. Med Care. 1992;30(5):400-411.

35. Johnson T, Fendrich M. Modeling Sources of Self-report Bias in a Survey of Drug Use Epidemiology. Ann Epidemiol. $2005 ; 15(5): 381-389$. 